\title{
Chlamydia pneumoniae antibodies are associated with an atherogenic lipid profile
}

\author{
L J Murray, D P J O’Reilly, G M L Ong, C O’Neill, A E Evans, K B Bamford
}

\begin{abstract}
Objective-To determine, within a representative population group of men and women, whether alteration of the lipid profile might underlie the reported association between Chlamydia pneumoniae and ischaemic heart disease.

Design and setting-Cross sectional survey in an area with a high incidence of ischaemic heart disease.

Subjects-400 randomly selected participants in the World Health Organisation MONICA project's third population survey in Northern Ireland.

Main outcome measures-Stored sera were examined by microimmunofluorescence for IgG antibodies to $C$ pneumoniae at a dilution of 1 in 64. Mean total and high density lipoprotein (HDL) cholesterol were compared between seropositive and seronegative individuals with adjustment for age, measures of socioeconomic status, smoking habit, alcohol consumption, body mass index, and the season during which blood had been taken.
\end{abstract}

Results-In seropositive men, adjusted mean serum total cholesterol and HDL cholesterol were $0.5 \mathrm{mmol} / 1$ (9.2\%) higher and $0.11 \mathrm{mmol} / 1(9.3 \%)$ lower, respectively, than in seronegative men. Differences in women did not achieve statistical significance, but both total cholesterol and HDL cholesterol were higher $(3.6 \%$ and $5.8 \%$, respectively) in seropositive than in seronegative individuals.

Conclusions-There is serological evidence that $C$ pneumoniae infection is associated with an atherogenic lipid profile in men. Altered lipid levels may underlie the association between $C$ pneumoniae and ischaemic heart disease. (Heart 1999;81:239-244)

Keywords: epidemiology; lipids; cholesterol; ischaemic heart disease

Chlamydia pneumoniae is a Gram negative obligate intracellular bacterium first described in $1986 .{ }^{1}$ It is principally a respiratory pathogen and is a common cause of community acquired pneumonia ${ }^{2}$ but the widespread prevalence of serological evidence of infection ${ }^{3-5}$ indicates that most $C$ pneumoniae infections may be subclinical. ${ }^{6}$ There is a substantial body of evidence relating $C$ pneumoniae infection to the development of ischaemic heart disease. The organism has been identified in atheromatous lesions of the coronary arteries and aorta, ${ }^{78}$ and with few exceptions ${ }^{9}$ both retrospective ${ }^{10-14}$ and prospective seroepidemiological studies ${ }^{15}$ have shown an association between evidence of $C$ pneumoniae infection and ischaemic events. This observational evidence of association is further supported by pilot intervention studies which indicate substantial reductions in secondary ischaemic events in survivors of myocardial infarction treated with antibiotics effective against $C$ pneumoniae. ${ }^{17}{ }^{18}$

Various mechanisms have been suggested whereby infection with $C$ pneumoniae may affect the risk of cardiovascular disease. Animal models have shown that $C$ pneumoniae easily gains access to the vascular system following pulmonary infection. ${ }^{19}$ Infection of endothelial or smooth muscle cells in vessel walls may occur, ${ }^{20}$ resulting in local inflammation and fibrosis and subsequent atheroma formation. Alternatively, repeated or persistent $C$ pneumoniae infection may stimulate the production of proinflammatory cytokines, ${ }^{21}$ which may increase the risk of cardiovascular disease ${ }^{22} 23$ by disturbing the basal thromboresistant function of vascular endothelial cells, ${ }^{24}$ inhibiting endothelium derived relaxing factor, ${ }^{24}{ }^{25}$ or affecting smooth muscle cell contractility. ${ }^{26}$ Recent research indicates that the risk of cardiovascular disease in $C$ pneumoniae infection may be mediated through a simpler process, namely the induction of an atherogenic lipid profile. ${ }^{27} 28$

We have investigated the relation between total and high density lipoprotein (HDL) cholesterol and evidence of $C$ pneumoniae infection in a population representative group of adult men and women from an area with a high incidence of ischaemic heart disease.

\section{Methods}

SURVEY METHODS

Subjects were drawn from those recruited in Northern Ireland into the World Health Organisation monitoring of trends and determinants in cardiovascular disease project's third population survey (MONICA 3). This survey employed a single stage random sampling procedure (sampling frame: the general practitioner patient register held by Central Services Agency, Belfast), with stratification by age and sex. Subjects were screened by trained observers adhering to a standard protocol ${ }^{29}$ between October 1991 and June 1992. Information collected by questionnaire included data on education and socioeconomic status, past medical history, drug treatment, and lifestyle (smoking habit, alcohol consumption, and diet). Height and weight were measured and a blood sample (not fasting) was taken, centrifuged, and separated within four hours. Serum from all subjects was analysed for total 
Table 1 Social class distribution of study subjects and Northern Ireland residents (25 to 64 years) at 1991 census

\begin{tabular}{|c|c|c|c|c|}
\hline \multirow[b]{2}{*}{ Social class } & \multicolumn{2}{|l|}{ Men } & \multicolumn{2}{|l|}{ Women } \\
\hline & $\begin{array}{l}\text { Study population } \\
(\%)\end{array}$ & $\begin{array}{l}\text { Northern Ireland } \\
\text { population (\%) }\end{array}$ & $\begin{array}{l}\text { Study population } \\
(\%)\end{array}$ & $\begin{array}{l}\text { Northern Ireland } \\
\text { population (\%) }\end{array}$ \\
\hline I & 8.4 & 5.1 & 4.8 & 1.7 \\
\hline II & 17.9 & 24.7 & 29.0 & 26.9 \\
\hline IIINM & 24.6 & 10.3 & 29.0 & 30.2 \\
\hline IIIM & 29.6 & 29.7 & 17.2 & 5.8 \\
\hline IV & 11.7 & 12.8 & 13.1 & 15.3 \\
\hline V & 7.8 & 5.3 & 6.9 & 10.3 \\
\hline
\end{tabular}

NM, non-manual; M, manual.

cholesterol (by the CHOD-PAP method) and HDL cholesterol (by precipitation employing phosphotungstic $\mathrm{Mg}^{2+}$ reagents). Serum not required for these assays was stored in aliquots at $-70^{\circ} \mathrm{C}$.

In this study, sera (thawed on one previous occasion) from 400 randomly selected subjects were analysed for the presence of anti-C pneumoniae antibodies. When serum was not available for one of the selected subjects, a replacement was randomly chosen.

LABORATORY METHODS

The MRL Diagnostics Chlamydia MIF (microimmunoflourescence) assay $^{30}$ was used to detect the presence of IgG antibodies to antigens from $C$ pneumoniae (TW183), $C$ psittaci (strains 6BC and DD34), and $C$ trachomatis (serotypes $\mathrm{D}-\mathrm{K}$ ) at a serum dilution of $1 / 64$. Slides were viewed at a magnification of $400 \times$ on a Leitz fluorescence microscope within 24 hours by two independent observers. Results were graded on a scale $0,+/-, 1+, 2+, 3+$ and $4+$ with 0 and $+/-$ interpreted as negative. If the observers disagreed on a result, the opinion of a third observer was sought. Subjects whose sera reacted with $C$ trachomatis or $C$ psittaci antigens were excluded from the analysis.

STATISTICAL/ANALYTICAL METHODS

Age, total cholesterol, HDL cholesterol, HDL/ total cholesterol ratio (expressed as a percentage of total cholesterol), body mass index, systolic blood pressure, and diastolic blood pressure were used in the analyses as continuous untransformed variables. Social class of the head of the household, tenure of accommodation, and highest educational level achieved were used as measures of socioeconomic status. Occupational class was coded according to the OPCS standard occupational classification $^{31}$ and was grouped into manual (IIIM, IV, and V) and non-manual (I, II, and IIINM) classes. Tenure was categorised into rented and owned, and highest educational level achieved categorised into elementary, primary or secondary school only, grammar school only, technical or nursing college, and third level education. Smoking habit was grouped into four categories: current smoker of 20 or more cigarettes a day, current smoker of less than 20 cigarettes a day, ex-smoker, and never smoked. Alcohol intake was categorised into lifetime abstinence, current abstinence, current alcohol intake less than 10 units per week, and current intake of more than 10 units per week. Month of screening was categorised as winter (November, December, January) or not winter (all other months).

Both bivariable (independent samples $t$ test, $\chi^{2}$ test, and $\chi^{2}$ test for trend) and multivariable analyses (multiple and logistic regression) were performed using SPSS for Windows. Multiple regression models were constructed with total cholesterol, HDL cholesterol, and HDL/total cholesterol ratio as dependent variables, and $C$ pneumoniae status as the independent variable, with covariables age, sex, occupational class, tenure of accommodation, highest educational level achieved, smoking status, alcohol intake, body mass index, and season of screening. Models were constructed for all subjects (with a sex/seropositivity interaction term included) and for men and women separately. These models were also constructed excluding subjects with a previous diagnosis of angina, myocardial infarction, or heart attack, and subjects providing responses to the Rose angina questionnaire in keeping with a diagnosis of definite or possible angina.

\section{Results}

In MONICA 3, 565 of 5000 subjects randomly selected from the Central Services Agency register were ineligible because they were deceased, resided outside the MONICA project area (Belfast and surrounding districts), or because their age was outside the specified range (25-64 years). A further 226 were not located after at least two visits to the last known address and reference to other sources. Of 4435 eligible subjects, 2005 participated in the project, giving a response rate of $45.2 \%$. Age and sex were available for all 2430 nonresponders, but only $317(13 \%)$ provided information on social class and so on. Overall, in MONICA 3 the male and female nonresponse rates were very similar - at 54.6\% and $54.9 \%$, respectively - and non-response rates were higher in the younger age groups $(64.4 \%$ and $62.2 \%$ in $25-34$ year old men and women, respectively, compared with $47.8 \%$ and $51.3 \%$ in the 55-64 year olds).

This report was based on sera from 393 subjects (199 men and 194 women). Seven of 400 randomly selected sera ( 52 replacements) were excluded, three and two because of cross reaction with $C$ psittaci and $C$ trachomatis antigens, respectively, and one sample had been tested twice with inconsistent results; therefore both samples were excluded. The random, sampling procedure used delivered a sample with characteristics (such as mean age, weight, total cholesterol, and so on) closely resembling all participants in MONICA 3.

The social class distribution of study subjects is compared to that of the Northern Ireland population at census in $1991^{32}$ (table 1). Professional occupations (both sexes), skilled non-manual occupations (in men) and skilled manual workers (women) were overrepresented in the study.

C PNEUMONIAE INFECTION, SOCIODEMOGRAPHIC AND LIFESTYLE VARIABLES

Overall, 276 sera $(70 \%)$ tested positively for anti-C pneumoniae IgG. The prevalence of anti- 
Table 2 Chlamydia pneumoniae seropositivity and social, biological, and lifestyle risk factors for ischaemic heart disease

\begin{tabular}{|c|c|c|c|c|c|}
\hline & & \multicolumn{2}{|l|}{ Men } & \multicolumn{2}{|l|}{ Women } \\
\hline & & $\begin{array}{l}\text { Mean }(S D) \text { in } \\
\text { seronegative men }\end{array}$ & $\begin{array}{l}\text { Mean (SD) in } \\
\text { seropositive men }\end{array}$ & $\begin{array}{l}\text { Mean }(S D) \text { in } \\
\text { seronegative women }\end{array}$ & $\begin{array}{l}\text { Mean (SD) in } \\
\text { seropositive women }\end{array}$ \\
\hline \multirow{5}{*}{$\begin{array}{l}\text { Age (years) } \\
\text { Diastolic blood pressure }(\mathrm{mm} \mathrm{Hg}) \\
\text { Systolic blood pressure }(\mathrm{mm} \mathrm{Hg}) \\
\text { Body mass index }\left(\mathrm{kg} / \mathrm{m}^{2}\right)\end{array}$} & & $44.9(11.5)$ & $45.3(11.4)$ & $42.6(12.2)$ & $45.6(11.1)$ \\
\hline & & $83.7(11.2)$ & $83.5(11.3)$ & $78.4(10.2)$ & $78.3(14.6)$ \\
\hline & & $135.4(19.1)$ & $132.3(18.4)$ & $127.0(19.3)$ & $127.8(23.1)$ \\
\hline & & $26.2(4.4)$ & $26.2(3.7)$ & $24.8(5.0)$ & $25.6(4.0)$ \\
\hline & & $\begin{array}{l}\text { Number (\%) } \\
\text { seronegative }\end{array}$ & $\begin{array}{l}\text { Number (\%) } \\
\text { seropositive }\end{array}$ & $\begin{array}{l}\text { Number (\%) } \\
\text { seronegative }\end{array}$ & $\begin{array}{l}\text { Number (\%) } \\
\text { seropositive }\end{array}$ \\
\hline \multirow[t]{2}{*}{ Social class } & Non-manual & $28(30.8)$ & $63(69.2)$ & $30(33.0)$ & $61(67.0)$ \\
\hline & Manual & $18(20.5)$ & $70(79.5)$ & $18(33.3)$ & $36(66.7)$ \\
\hline \multirow[t]{2}{*}{ Tenure } & Owned & $44(27.2)$ & $118(72.8)$ & $50(31.6)$ & $108(68.4)$ \\
\hline & Rented & $9(27.3)$ & $24(72.7)$ & $10(38.5)$ & $16(61.5)$ \\
\hline \multirow[t]{4}{*}{ Highest educational level achieved } & Primary, elementary or secondary school only & $25(21.0)$ & $94(79.0)$ & $34(30.4)$ & $78(69.6)$ \\
\hline & Grammar school & $6(24.0)$ & $19(76.0)$ & $6(37.5)$ & $10(62.5)$ \\
\hline & Technical/polytech/nursing college & $12(54.5)$ & $10(45.5)$ & $13(34.2)$ & $25(65.8)$ \\
\hline & University & $10(32.3)$ & $21(67.7)$ & $8(34.8)$ & $15(65.2)$ \\
\hline \multirow[t]{4}{*}{ Smoking status } & Never smoked & $21(28.4)$ & $53(71.6)$ & $30(32.6)$ & $62(67.4)$ \\
\hline & Ex-smoker & $14(23.0)$ & $47(77.0)$ & $16(35.6)$ & $29(64.4)$ \\
\hline & Current smoker less than 20 /day & $5(20.8)$ & $19(79.2)$ & $12(34.3)$ & $23(65.7)$ \\
\hline & Current smoker 20 or more/day & $14(35.0)$ & $26(65.0)$ & $3(16.7)$ & $15(83.3)$ \\
\hline \multirow[t]{4}{*}{ Alcohol consumption } & Lifetime abstainer & $6(46.2)$ & $7(53.8)$ & $10(28.6)$ & $25(71.4)$ \\
\hline & Current abstainer & $1(7.1)$ & $13(92.9)$ & $3(17.6)$ & $14(82.4)$ \\
\hline & Current drinker $<10$ units/week & $18(25.7)$ & $52(74.3)$ & $36(33.6)$ & $71(66.4)$ \\
\hline & Current drinker 10 or more & $27(27.3)$ & $72(72.7)$ & $12(41.4)$ & $17(58.6)$ \\
\hline \multirow[t]{2}{*}{ Season } & Not winter & $42(31.1)$ & $93(68.9)$ & $42(35.9)$ & $75(64.1)$ \\
\hline & Winter & $12(18.7)$ & $52(81.3)$ & $22(28.6)$ & $55(71.4)$ \\
\hline
\end{tabular}

C pneumoniae IgG was not related to age, but seropositivity was slightly (although not significantly) more common in men than in women $(72.9 \%$ v $67.0 \%)$. Seropositivity was more common in subjects from manual than non-manual social classes, but statistical significance was not achieved for either sex (table 2). There was no association between seropositivity and tenure of accommodation but a significant trend towards lower prevalence of infection with higher level of educational achievement was evident in men $\left(\chi^{2}\right.$ 5.3, df $1, \mathrm{p}=0.02$ ).

$C$ pneumoniae seropositivity was not related to smoking habit, alcohol consumption, anthropometric measurements (height, weight, and body mass index), or systolic or diastolic blood pressure in either sex. Infection was more common in men screened during winter than in men screened during the rest of the year $(81.3 \%$ seropositive $v 68.9 \%)$, although this relation did not reach conventional statistical significance $\left(\chi^{2} 3.35\right.$, df $\left.1, \mathrm{p}=0.07\right)$.

C PNEUMONIAE INFECTION AND LIPIDS

In this dataset, age, living in rented accommodation, and having high body mass index $(>25$ $\mathrm{kg} / \mathrm{m}^{2}$ ) were associated with raised total serum cholesterol, while being female, not smoking, and having low body mass index were associated with raised HDL cholesterol.

The unadjusted and adjusted associations between seropositivity for $C$ pneumoniae and lipids are shown in table 3. Total cholesterol was significantly higher and HDL cholesterol and the HDL/total cholesterol ratio significantly lower in seropositive men than in seronegative men. In women, being seropositive was also associated with raised total cholesterol, although the association did not reach levels of conventional statistical significance. Seropositive women tended to have higher, rather than lower, HDL cholesterol and a sex/ seropositivity interaction term included in the model for HDL cholesterol involving all subjects achieved statistical significance.

Thirty four subjects $(8.6 \%, 20$ male and 14 female) had a history of angina, myocardial infarction, or heart attack or gave responses to the Rose angina questionnaire in keeping with definite or possible angina. Exclusion of these subjects from the regression models made a minimal difference to the adjusted relations

Table 3 Chlamydia seropositivity and lipid levels

\begin{tabular}{|c|c|c|c|c|c|c|c|c|}
\hline & \multicolumn{4}{|l|}{ Men } & \multicolumn{4}{|l|}{ Women } \\
\hline & \multicolumn{2}{|c|}{ Serology status } & \multicolumn{2}{|c|}{ Mean difference $(95 \% \mathrm{CI})$} & \multicolumn{2}{|c|}{ Serology status } & \multicolumn{2}{|c|}{ Mean difference $(95 \% \mathrm{CI})$} \\
\hline & Positive & Negative & Unadjusted & Adjusted & Positive & Negative & Unadjusted & Adjusted \\
\hline Total cholesterol (mmol/1) & $5.46(1.01)$ & $5.86(0.96)$ & $\begin{array}{l}0.4 \\
(0.09 \text { to } 0.72)^{\star}\end{array}$ & $\begin{array}{l}0.5 \\
(0.15 \text { to } 0.87)^{\star \star}\end{array}$ & $5.76(1.30)$ & $6.00(1.40)$ & $\begin{array}{l}0.24 \\
(-0.18 \text { to } 0.62)\end{array}$ & $\begin{array}{l}0.21 \\
(-0.17 \text { to } 0.59)\end{array}$ \\
\hline HDL cholesterol $(\mathrm{mmol} / \mathrm{l})$ & $1.18(0.27)$ & $1.07(0.38)$ & $\begin{array}{l}-0.11 \\
(-0.20 \text { to }-0.02)^{\star}\end{array}$ & $\begin{array}{l}-0.11 \\
(-0.21 \text { to } 0)^{\star}\end{array}$ & $1.37(0.31)$ & $1.39(0.33)$ & $\begin{array}{l}0.02 \\
(-0.08 \text { to } 0.11)\end{array}$ & $\begin{array}{l}0.08 \\
(-0.02 \text { to } 0.18)\end{array}$ \\
\hline $\mathrm{HDL} /$ total cholesterol ratio & $22.1(5.7)$ & $18.7(7.9)$ & $\begin{array}{l}-3.4 \\
(-5.3 \text { to }-1.4)^{\star \star}\end{array}$ & $\begin{array}{l}-3.5 \\
(-5.7 \text { to }-1.4)^{\star \star}\end{array}$ & $25.4(7.1)$ & $24.3(8.8)$ & $\begin{array}{l}-1.1 \\
(-3.4 \text { to } 1.26)\end{array}$ & $\begin{array}{l}-0.2 \\
(-2.1 \text { to } 2.5)\end{array}$ \\
\hline
\end{tabular}

Values are means (SD) or $95 \%$ confidence intervals (CI). Adjustments were made for age (years), sex, manual/non-manual occupational class, tenure of accommodation, highest educational level achieved, smoking habit, alcohol consumption, body mass index, and season of screening. ${ }^{\star} \mathrm{p}<0.05 ;{ }^{\star \star} \mathrm{p}<0.01$ 
between seropositivity and lipid levels. The significance, magnitude, and direction of effects were unaltered with one exception. The adjusted mean difference in HDL cholesterol in seropositive compared with seronegative men $(-0.11,95 \%$ confidence interval -0.22 to 0.01 ), although unaltered in magnitude and direction, no longer achieved conventional statistical significance $(p=0.07)$. The sex/ seropositivity interaction term achieved statistical significance when included in the model for HDL cholesterol involving all subjects without symptomatic-or a history of symptomatic - ischaemic heart disease.

\section{Discussion}

In this study we examined the relation between seropositivity for IgG antibodies to $C$ pneumoniae and lipid levels. Possession of IgG antibodies to $C$ pneumoniae is evidence of exposure to the organism but a single measurement will not distinguish between a primary infection, a repeat infection, or a chronic infection. Reinfection with $C$ pneumoniae is common and most acute infections in adulthood are reinfections. ${ }^{33}$ Chronicity is a feature of the genus and there is evidence that infection with $C$ pneumoniae may persist for many months. ${ }^{34}$ The presence of IgG antibodies in the sera of subjects in this study (all adults) could therefore be interpreted as evidence of repeat, chronic, or latent infection with $C$ pneumoniae, although resolved infection with persistence of IgG cannot be excluded. If the presence of anti-IgG antibodies to $C$ pneumoniae merely denotes acute infection, then the relation between $C$ pneumoniae and an atherogenic lipid profile found in this study may be entirely the product of an acute phase reaction following the acute infection. If this is the case the disturbance of the lipid profile could be expected to be short lived and with presumably no accompanying increased risk of atherosclerosis. However, it is unlikely that $70 \%$ of the subjects studied had a recent infection with $C$ pneumoniae, even if it was asymptomatic. It may be more likely that possession of IgG antibody to $C$ pneumoniae denotes either previous exposure (with antibody persistence) or chronic or latent infection. If IgG denotes only previous exposure-for example, in childhood, perhaps the relation between evidence of infection and the lipid profile is confounded by an unrecognised factor. But if IgG seropositivity denotes chronic, latent, or even frequent repeat infection, the alteration of the lipid profile we have observed in men may also be chronic and contribute to atherogenesis.

Previous studies showing an association between $C$ pneumoniae infection and lipid levels ${ }^{27} 28$ largely ignored the role that confounding may have played in their findings. Several factors may confound this association-for example, low socioeconomic status has been related to both raised total cholesterol $^{35-37}$ and $C$ pneumoniae infection, ${ }^{3}$ although these are not consistent findings. ${ }^{12}{ }^{38-40}$ Smoking is a recognised risk factor for $C$ pneumoniae infection ${ }^{40}{ }^{41}$ and is associated with low HDL cholesterol. ${ }^{42}{ }^{43}$ Simi- larly, alcohol intake i4 $^{45}$ and body mass index ${ }^{42} 46$ are strongly associated with HDL cholesterol and although there is no evidence that they are related to $C$ pneumoniae infection, it was felt that the epidemiology of the infection was not sufficiently known to allow them to be excluded as potential confounders. Blood pressure is unlikely to confound a relation between seropositivity and lipids, as blood pressure is not known to influence lipid levels directly and, in this study, systolic and diastolic blood pressure were not associated with $C$ pneumoniae seropositivity.

The date at which blood was collected may also have confounded the association. Seasonal variation in total cholesterol and HDL cholesterol is a recognised phenomenon, with the total cholesterol peak ${ }^{47-49}$ and HDL cholesterol trough $^{50}{ }^{51}$ usually occurring during the winter months. Although, seasonal variation in lipid levels was not observed in this study, subjects screened in winter had a higher prevalence of anti-C pneumoniae antibodies than those screened during the rest of the year. This is in keeping with the findings of other investigators. ${ }^{11}$

The relations between $C$ pneumoniae and lipid levels were therefore adjusted for available measures of socioeconomic status, smoking habit, alcohol intake, body mass index, and season of blood collection. The effect of the adjustments was to accentuate the relations in men, with adjustment for measures of socioeconomic status contributing most to the increase in strength.

It is theoretically possible that, if $C$ pneumoniae infection is related to ischaemic heart disease by a mechanism other than disturbance of the lipid profiles, any disturbance in lipid levels seen in $C$ pneumoniae positive individuals may be caused by abnormal lipid profiles occurring in those with ischaemic heart disease. If this were the case then the seropositivity/lipid relations observed in this study could be expected to be markedly attenuated by excluding from analyses those subjects with evidence of ischaemic heart disease. However, these associations remained substantially unaltered following the exclusion of subjects with symptomatic - or a history of symptomaticischaemic heart disease. Residual confounding resulting from an inability to identify and exclude subjects with asymptomatic ischaemic heart disease remains a possibility.

It is conceivable that the observed association between $C$ pneumoniae seropositivity and lipid levels may be the product of selection bias introduced through poor response rates. However, for this to occur, individuals with low total cholesterol (or high HDL cholesterol) who were positive for anti-C pneumoniae IgG or persons negative for anti- $C$ pneumoniae IgG and with high total cholesterol (or low HDL cholesterol) would have to have opted out. Given the high prevalence of the infection and lack of association with social class, age, and sex (in this study), it is unlikely that this would have occurred. Residual confounding by an unrecognised factor, or inadequate adjustment for identified confounders, may also explain 
our findings - a possibility which cannot be eliminated until the basic epidemiology of $C$ pneumoniae infection is more clearly elucidated.

The findings of this study are consistent with the observation by Laurila et $a l{ }^{27}$ in a cross sectional study of male reindeer herders in Northern Finland, of decreased HDL and $\mathrm{HDL} /$ total cholesterol ratio in subjects with serological evidence of $C$ pneumoniae infection. However, as in other studies of $C$ pneumoniae infection in which total cholesterol was measured, ${ }^{11} 124052$ Laurila et al did not observe an association between seropositivity and cholesterol levels, though in a follow up study total cholesterol was raised in subjects with evidence of chronic infection..$^{28}$ Raised triglyceride levels have also been observed in persons with evidence of $C$ pneumoniae infection. ${ }^{27} 40$

The most commonly reported infection induced lipid abnormalities in man and experimental animals have been decreased HDL cholesterol and raised triglycerides and very low density lipoprotein. ${ }^{53-55}$ These effects are part of the acute phase response, appear to be mediated by cytokines such as tumour necrosis factor, interleukin (IL)-1, and IL- $6,{ }^{54}$ and have been observed in persons with serological evidence of $C$ pneumoniae infection. ${ }^{27}$ The effect of infection on total and LDL cholesterol is less clear. In rodent models, increases in total cholesterol have been seen following lipopolysaccharide challenge,${ }^{53}{ }^{56}$ but it has consistently been reported in man and primates that total and LDL cholesterol values decrease in severe bacterial infections, including community acquired pneumonias. ${ }^{53557}$ Decreases in total and HDL cholesterol have also been shown in humans with minor illnesses (including minor infections), ${ }^{58} 59$ and these lipid changes are not the result of dietary changes. ${ }^{59}$ Therefore it appears that in humans the lipid component of the acute phase response to infection involves an increase in triglycerides and a decrease in total, LDL cholesterol, and HDL cholesterol.

The acute phase response to infection may therefore explain the association observed in the present study between $C$ pneumoniae seropositivity and lowered HDL cholesterol but does not convincingly explain raised total cholesterol. The lipid response to chronic infection may be different from that which occurs in acute infection. Laurila et al have observed raised total cholesterol in Finnish men with serological evidence of chronic $C$ pneumoniae infection, ${ }^{28}$ but the relation was only seen in non-smokers and the association was not adjusted for other potential determinants of raised total cholesterol. It is possible that a significant proportion of our subjects testing positive for $C$ pneumoniae antibodies have a chronic rather than an acute infection. If this is the case, our findings would be consistent with those of Laurila et al but this would require the assumption that the lipid response to chronic infection is substantially different from that of acute infection. Studies of-for example, Helicobacter pylori infection (a chronic gastric infection) have not provided such evidence. ${ }^{406061}$
This is the first study to examine the relation between infection with $C$ pneumoniae and lipid levels in both men and women. In both sexes we observed an effect on total cholesterol in the same direction, but infected men had lower HDL cholesterol concentrations while infected women had higher concentrations. Addition of a sex/seropositivity term to the HDL model confirmed this sex specific difference in direction of effect. As few biological processes show opposite effects between the sexes, and there is no evidence that the acute phase response is different in women and men, this finding must be regarded with caution until confirmed by other investigators.

We have, however, demonstrated an epidemiologically robust association between an atherogenic lipid profile and evidence of infection with $C$ pneumoniae and, although the possible mechanism of action may not be clear, this finding may have substantial public health implications. If treatment of $C$ pneumoniae infection resulted in a sustained reduction in total cholesterol similar in magnitude to the increase seen in infected subjects in this study, data from meta-analyses of cholesterol lowering trials ${ }^{62}{ }^{63}$ indicate an expected decrease in the risk of ischaemic heart disease in treated individuals (potentially $70 \%$ of the population) of at least $20 \%$. Further investigation in this area is essential to determine whether the atherogenic lipid profile in $C$ pneumoniae infection is sustained or recurs with repeated infection sufficiently often to alter long term cardiovascular disease risk, and to determine if relatively simple antibiotic treatment can substantially reduce the risk of cardiovascular disease.

1 Grayston JT, Kuo C-C, Wang S-P, et al. A new Chlamydia psittaci strain, TWAR, isolated in acute respiratory tract infections. N Engl F Med 1986;315:161-8.

2 Cook PJ, Honeybourne D. Clinical aspects of Chlamydia pook PJ, Honeybourne D. Clinical aspects of Ch

3 Paltiel O, Kark JD, Leinonen M, et al. High prevalence of antibodies to Chlamydia pneumoniae: determinants of IgG seropositivity among Jerusalem residents. Epidemiol Infect 1995;114:465-73.

4 Freidank HM, Brauer D. Prevalence of antibodies to C. pneumoniae TWAR in a group of German medical students. F Infect 1993;27:89-93.

5 Van den Abeele AM, Van Renterghem L, Willems K, et al. Prevalence of antibodies to Chlamydia pneumoniae in a Belgian population. F Infect 1992;25 (suppl 1):87-90.

6 Kuo CC, Jackson LA, Campbell LA, et al. Chlamydia pneumoniae (TWAR). Clin Microbiol Rev 1995;8:451-61.

7 Kuo CC, Shor A, Campbell LA, et al. Demonstration of Chlamydia pneumoniae in atherosclerotic lesions of coron-

8 Grayston TG. Chlamydia in atherosclerosis. Circulation 1993;87:1408-9.

9 Kark JD, Leinonen M, Paltiel O, et al. Chlamydia pneumoniae and acute myocardial infarction in Jerusalem. Int 7 Epidemiol 1997;26:730-8.

10 Linnanmaki E, Leinonen M, Mattila K, et al. Chlamydia pneumoniae-specific circulating immune complexes in patients with chronic coronary heart disease. Circulation 1993;87:1130-4.

11 Thom DH, Grayston JT, Siscowick DS, et al. Association of prior infection with Chlamydia pneumoniae and angiographically demonstrated coronary artery disease. $\mathcal{F A M A}$ 1992;268:68-72.

12 Mendall M, Carrington D, Strachan D, et al. Chlamydia pneumoniae: risk factors for seropositivity and association with coronary heart disease. $\mathcal{F}$ Infect 1995;30:121-8.

13 Saikku P, Mattila K, Niemenen MS, et al. Serological evidence of an association of a novel Chlamydia, TWAR, with chronic coronary heart disease and acute myocardial infarction. Lancet 1988;ii:983-5.

14 Dahlen GH, Boman J, Birgander LS, et al. Lp(a) lipoprotein, IgG, IgA, IgM antibodies to Chlamydia pneumoniae and HLA class II genotype in early coronary artery moniae and HLA class II genotype in ear

15 Saikku P, Leinonen M, Tenkanen L, et al. Chronic Chlamydia pneumoniae infection as a risk factor for coronary heart 
disease in the Helsinki heart study. Ann Intern Med 1992;116:273-8.

16 Miettinen $H$, Lehto $S$, Saikku $P$, et al. Association of Chlamydia pneumoniae and acute coronary heart disease in non-insulin dependent diabetic and non-diabetic subjects in Finland. Eur Heart f 1996;17:682-8.

17 Gupta S, Leatham EW, Carrington D, et al. Elevated Chlamydia pneumoniae antibodies, cardiovascular events and azithromycin in male survivors of myocardial infarction. Circulation 1997;96:404-7.

18 Gurfinkel E, Bozovich G, Daroca A, et al. Randomised controlled trial of roxithromycin in non-Q wave syndromes: Roxis pilot study. Lancet 1997;350:404-7.

19 Moazed TC, Kuo C, Grayston JT, et al. Murine models of Chlamydia pneumoniae infection and atherosclerosis. $f$ Infect Dis 1997;175:883-90.

20 Gaydos CA, Summersgill JT, Sahney NN, et al. Replication of Chlamydia pneumoniae in vitro in human macrophages, endothelial cells and aortic artery smooth muscle cells. Infect Immun 1996;64:1614-20.

21 Gupta S, Leatham EW. The relation between Chlamydia pneumoniae and atherosclerosis. Heart 1997;77:7-8.

22 Mendall MA, Patel P, Asante M, et al. Relation of serum cytokine concentration to cardiovascular risk factors and cytokine concentration to cardiovascular risk

23 Tashiro H, Shimokawa H, Yamamoto K, et al. Altered plasma levels of cytokines in patients with ischaemic heart disease. Coron Artery Dis 1997;8:143-7.

24 Vallance P, Collier J, Bhagat K. Infection, inflammation and infarction: does acute endothelial dysfunction provide the link. Lancet 1997;349:1391-2.

25 Myers PR, Parker JL, Tanner MA, et al. Effects of cytokines tumour necrosis factor alpha and interleukin 1 beta on endotoxin-medicated inhibition of endothelium-derived relaxing factor bioactivity and nitric oxide production in vascular endothelium. Shock 1994;1:73-8.

26 Fukumoto Y, Shimokawa H, Ito A, et al. Inflammatory cytokines cause coronary arteriosclerosis-like changes and alterations in the smooth-muscle phenotypes in pigs. 7 Cardiovasc Pharmacol 1997;29:222-31.

27 Laurila A, Bloigu A, Nayha S, et al. Chlamydia pneumoniae antibodies and serum lipids in Finnish men: cross sectional antibodies and serum lipids in

28 Laurila A, Bloigu A, Nayha S, et al. Chronic Chlamydia pneumoniae infection is associated with a serum lipid profile known to be a risk factor for atheros Thromb Vasc Biol 1997;17:2810-13.

29 Cardiovascular Diseases Unit. MONICA manual. WHO MONICA Project. Geneva: World Health Organisation.

30 Freidank HM, Vogele H, Eckert K. Evaluation of a new commercial microimmunofluorescence test for detection of antibodies to Chlamydia pneumoniae, Chlamydia trachomatis, and Chlamydia psittaci. Eur 7 Clin Microbiol Infect Dis 1997; 16:685-8.

31 Office of Population Censuses and Surveys GSS. Standard occupational classification. London: HMSO.

32 The Northern Ireland Census 1991. Belfast: HMSO, 1993.

33 Aldous M, Grayston JT, Wang S-P, et al. Seroepidemiology of Chlamydia pneumoniae TWAR infection in Seattle of Chlamydia pneumoniae TWAR infection in

34 Hammerschlag MR, Chirgwin K, Roblin PM, et al. Persistent infection with Chlamydia pneumoniae following acute
respiratory illness. Clin Infect Dis 1992;14:178-82.

35 Leino M, Porkka KV, Raitakari OT, et al. Influence of parental occupation on coronary heart disease risk factors in children. Int $\mathcal{F}$ Epidemiol 1996;25:1189-95.

36 Myllykangas M, Pekkanen J, Rasi V, et al. Haemostatic and other cardiovascular risk factors, and socio-economic status among middle-aged Finnish men and women. Int $f$ Epidemiol 1995;24:1110-16.

37 Winkleby MA, Fortmann SP, Barrett DC. Social class disparities in risk factors for disease: eight year prevalence patterns by level of education. Prev Med 1990;19:1-12.

38 Shewry MC, Smith WC, Woodward M, et al. Variation in coronary risk factors by social status: results from the Scottish heart health study. Br f Gen Pract 1992;42:406-10.

39 Smith GD, Shipley MJ, Rose G. Magnitude and causes of socio-economic differentials in mortality: further evidence socio-economic differentials in mortality: further evidence
from the Whitehall Study. 7 Epidemiol Community Health from the Whiteh

40 Patel P, Mendall MA, Carrington D, et al. Association of Helicobacter pylori and Chlamydia pneumoniae infections with coronary heart disease and cardiovascular risk factors. BMF 1995;311:711-14.

41 Karvonen M, Tuomilehto J, Pitkaniemi J, et al. Importance of smoking for Chlamydia pneumoniae seropositivity. Int $\mathcal{F}$ Epidemiol 1994;23:1315-21.

42 Thelle DS, Shaper AG, Whitehead TP, et al. Blood lipids in middle-aged British men. Br Heart f 1983;49:205-13.

43 Fortmann SP, Haskell WL, Williams PT. Changes in plasma high density lipoprotein cholesterol after changes in cigarette use. Am f Epidemiol 1986;124:706-10.

44 Clevidence BA, Reichman ME, Judd JT, et al. Effects of alcohol consumption on lipoproteins of premenopausal women. A controlled diet study. Arterioscler Thromb Vasc Biol 1995;15:179-84.

45 Burr ML, Fehily AM, Butland BK, et al. Alcohol and high density lipoprotein cholesterol: a randomised controlled trial. Br 7 Nutr 1986;56:81-6.

46 Van Horn LV, Ballew C, Liu K, et al. Diet, body size, and plasma lipids-lipoproteins in young adults: differences by race and sex. The coronary artery risk development in young adults (CARDIA) study. Am f Epidemiol 1991;133: 9-23.

47 Rastam L, Hannan PJ, Luepker RV, et al. Seasonal variation in plasma cholesterol distributions: implications for screening and referral. Am f Prev Med 1992;8:360-6.

48 Woodhouse PR, Khaw KT, Plummer M. Seasonal variation of serum lipids in an elderly population. Age Ageing 1993;22:273-8.

49 Robinson D, Hinohara S, Bevan EA, et al. Seasonal variation in serum cholesterol levels in health screening populations from the UK and Japan. 7 Med Syst 1993; 17:207-11.

50 Mantarri M, Javela K, Koskinen P, et al. Seasonal variation in high density lipoprotein cholesterol. Atherosclerosis 1993; 100:257-65.

51 Frohlich M, Sund M, Russ S, et al. Seasonal variations of rheological and haemostatic parameters and acute-phase reactants in young, healthy subjects. Arterioscler Thromb Vasc Biol 1997;17:2692-7.

52 Cook PJ, Honeybourne D, Lip GY, et al. Chlamydia pneumoniae antibody titres are significantly associated with acute stroke and transient cerebral ischemia: the West Birmingham stroke project. Stroke 1998;29:404-10.

53 Lopes-Virella MF. Interactions between bacterial lipopolysaccharides and serum lipoproteins and their possible role in coronary heart disease. Eur Heart $f$ 1993;14(suppl $\mathrm{K}): 118-24$.

54 Feingold K, Grunfeld C. Role of cytokines in inducing hyperlipidaemia. Diabetes 1992;41(suppl 2):97-101.

55 Sammalkorpi KT, Valtonen VV, Maury CP. Lipoproteins and acute phase response during acute infection. Interrelationships between C-reactive protein and serum amyloid-A protein and lipoproteins. Ann Med 1990;22:397-401.

56 Feingold KR, Hardardattir I, Memon R, et al. Effect of endotoxin on cholesterol biosynthesis and distribution in serum lipoproteins in Syrian hamsters. 7 Lipid Res 1993;34: $2147-58$.

57 Rodriguez Reguero JJ, Iglesias Cubero G, Vazquez M, et al. Variation in plasma lipid and lipoprotein concentrations in community-acquired pneumonia: a six-month prospective study. Eur f Clin Chem Clin Biochem 1996;34:245-9.

58 Jacobs DRI, Hebert B, Schreiner PJ, et al. Reduced cholesterol is associated with recent minor illness: the CARDIA study. Coronary artery risk development in young adults. Am f Epidemiol 1997;146:558-64.

59 Hyman DJ, Barrett DC, Fortmann SP. Effect of minor illness on serum cholesterol level. Am $f$ Prev Med 1992;8:100-3.

60 Murray LJ, Bamford KB, O'Reilly DPJ, et al. Helicobacter pylori infection: relation with cardiovascular risk factors, 74:497-501.

61 Scragg RKR, Fraser A, Metcalf PA. Helicobacter pylori seropositivity and cardiovascular risk factors in a multicultural workforce. F Epidemiol Community Health 1996;50: $578-9$.

62 Wald NJ, Law MR. Serum cholesterol and ischaemic heart disease. Atherosclerosis 1995;118(suppl):S1-5.

63 Law MR, Wald NJ, Thompson SG. By how much and how quickly does reduction in serum cholesterol lower risk of ischaemic heart disease? BMF 1994;308:367-72. 